\title{
PENGARUH MOTIVASI, KOMPENSASI DAN LINGKUNGAN KERJA TERHADAP KEPUASAN KERJA KARYAWAN (STUDI PADA CV ENGGAL JAYA SEMARANG)
}

\author{
Areis Prassetiawan \\ Dian Triyani \\ Fakultas Ekonomi Universitas Semarang (USM)
}

Diterima: April 2018. Disetujui: Juli 2018. Dipublikasikan: Oktober 2018

\begin{abstract}
This study aims to examine or determine how much influence the variable motivation, compensation, and work environment on job satisfaction.

This study was conduced on employees CV Enggal Jaya Semarang. Techniques used in the sampling in this research is to use a sampling technique that is saturated or census sampling when all members of the population used as a sample. Data collected by spreading questionnaire. Method of data analysis performed by multiple linear regresion using SPSS 20 software testing technique of data used in this study include the validity, reliability with Alpha Conbranch. Clasical assumption test, multiple linear regresion test, $t$ test, and multiple determination coefficient was used to test and prove the research hypothesis.

The result showed that the variable motivation, compensation, and work environment and a significant positive effect on job satisfaction. By hypothesis testing using $t$-test showed that the three independent variables studied proved positively and significantly affect the variable.
\end{abstract}

Keywords : Motivation, Compensation, Work Environment and Job Satisfaction

\begin{abstract}
ABSTRAK
Penelitian ini bertujuan untuk menguji atau mengetahui seberapa besar pengaruh variabel motivasi, kompensasi, dan lingkungan kerja terhadap kepuasan kerja.

Penelitian ini dilakukan terhadap karyawan CV Enggal Jaya Semarang. Tekhnik yang digunakan dalam pengambilan sampel dalam penelitian ini adalah dengan tekhnik sampling jenuh atau sensus yaitu penentuan sampel bila semua anggota populasi digunakan sebagai sampel. Pengumpulan data dilakukan dengan wawancara dan menyebar kuesioner. Metode analisis data dilakukan dengan regresi linear berganda menggunakan software SPSS 20. Tekhnik pengujian data yang digunakan dalam penelitian ini meliputi uji validitas, uji reliabilitas dengan Alpha Concbranch. Uji asumsi klasik, uji regresi linear berganda, uji t, dan koefisien determinasi berganda digunakan untuk menguji dan membuktikan hipotesis penelitian.

Hasil penelitian menunjukan dimana variabel Motivasi, Kompensasi, Lingkungan Kerja berpengaruh positif dan signifikan terhadap Kepuasan Kerja. Dengan pengujian hipotesis menggunakan uji-t menunjukan bahwa ketiga variabel independen yang diteliti terbukti secara positif dan signifikan mempengaruhi variabel dependen.
\end{abstract}

Kata Kunci : Motivasi, Kompensasi, Lingkungan Kerja dan Kepuasan Kerja.

\section{PENDAHULUAN}

Keberhasilan sebuah organisasi sangat didukung oleh bagaimana organisasi mencapai kepuasan kerja pegawainya. Secara umum, kepuasan kerja mengarah kepada sikap dari individu tersebut terhadap pekerjaanya. Para karyawan yang 
mempunyai sikap yang positif maka memiliki tingkat kepuasan kerja yang tinggi, demikian juga sebaliknya Mathis dan Jackson (2008: 100). Reaksi positif dan negative terlihat pada pegawai tergantung dari kepuasan kerja yang mereka dapatkan. Pegawai akan merasakan semangat kerja yang tinggi dan kegairahan dalam memulai pekerjaannya jika kepuasan kerja tercapai, namun jika tidak tercapai maka pegawai berusaha menghindari lingkungan sosialnya seperti mengundurkan diri dari perusahaan, bolos kerja, melakukan sabotase, sengaja melakukan kesalahan dalam bekerja, aktif pemogokan dan perilaku lain yang cenderung bersifat menghindari aktivitas organisasi (Sutrisno, 2009:83).

Motivasi memiliki peranan penting dalam kepuasan kerja karyawan. Menurut Winardi (Maznah, 2012) motivasi adalah keinginan yang terdapat pada seorang individu yang merangsangnya melakukan tindakan. Gomes (2009:177) menyatakan motivasi berkaitan erat dengan keberhasilan perusahaan dalam mencapai tujuan. Menurut Jugde et al (2001) harapan berbasis teori motivasi secara umum menetapkan bahwa kepuasan mengikuti dari manfaat yang dihasilkan kinerja.

Kompensasi merupakan salah satu faktor yang mempengaruhi kepuasan kerja seorang karyawan. Setiap organisasi sebaiknya berupaya untuk meningkatkan kepuasan kerja karyawannya dengan memberikan program kompensasi yang adil dan layak serta kompetitif. Handoko (2001: 155) menyatakan pemberian kompensasi dapat meningkatkan kepuasan kerja karyawan. Kompensasi bisa dirancang secara benar untuk mencapai keberhasilan bersama sehingga karyawan merasa puas dengan jerih payah mereka dan termotivasi untuk mencapai tujuan dan sarana bersama manajemen (Rachmawati, 2008:143). Kompensasi yang diberikan perusahaan kepada karyawan dapat memberikan manfaat jangka panjang dan pendek perusahaan karena kompensasi berfungsi dan bertujuan untuk ikatan kerjasama perusahaan dengan karyawan, peningkatan kepuasan kerja, pengadaan yang efektif, memotivasi, menjaga stabilitas karyawan, menjaga kedisiplinan karyawan, penghindaran serikat buruh dan pengaruh intervensi pemerintah (Ardana, dkk., 2012:154). 
Lingkungan kerja memiliki kontribusi yang signifikan bagi kepuasan kerja karyawan (Holman, 2002), sehingga lingkungan kerja karyawan memiliki efek yang kuat terhadap kepuasan kerja (Hurley et al., 2000). Lingkungan kerja merupakan kondisi dari segala sesuatu yang terdapat di sekitar tempat bekerja karyawan yang mampu memberikan pengaruh bagi dirinya dalam melaksanakan pekerjaannya (Nitisemito, 2006:106). Kepuasan akan lebih tinggi dan niat untuk meninggalkan akan lebih rendah bila lingkungan kerja melengkapi persyaratan kreativitas pekerjaan (Shalley et al., 2000).

CV ENGGAL JAYA Semarang merupakan salah satu perusahaan yang bergerak dibidang otomotif yaitu karoseri dan bengkel mesin. CV ENGGAL JAYA berlokasi di J1. Pedurungan Tengah XII No.7 Semarang mempunyai karyawan sebanyak 60 karyawan. Karyawan merupakan objek yang akan diteliti oleh penulis. Dari data yang didapat menunjukan adanya salah satu indikator penurunan kepuasan kerja, yaitu bertambahnya tingkat ketidak hadiran karyawan, dengan bertambahnya jumlah absensi karyawaan memungkinkan adanya indikasi kepuasan kerja karyawan yang menurun, maka hal tersebut akan berpengaruh terhadap tujuan organisasi. Bertambahnya jumlah absensi karyawan juga merupakan wujud ketidak puasan karyawan dalam bekerja. Karyawan yang tidak puas cenderung bersikap seenaknya sendiri karena mereka beranggapan bahwa sebaik apapun mereka bekerja mereka merasa tidak mendapatkan balasan yang layak dari perusahaan.

Penelitian yang dilakukan oleh Ida Ayu Brahmasari dan Agus Suprayetno (2008) menyimpulkan adanya pengaruh positif antara motivasi kerja terhadap kepuasan kerja. Penelitian lain yang dilakukan oleh Fauzan Muttaqien (2014) menyatakan juga ada pengaruh antara kompensasi terhadap kepuasan kerja. Anak Agung Ngurah Bagus Dharmawan, I gede Adayana Sudibya, dan I Wayan Muddhiarta Utama (2012) menyimpulkan bahwa lingkungan kerja berpengaruh signifikan terhadap kepuasan kerja.

\section{TINJAUAN PUSTAKA}




\section{Manajemen Sumber Daya Manusia}

Manajemen sumber daya manusia merupakan suatu usaha untuk mengarahkan dan mengelola sumber daya manusia di dalam suatu organisasi agar mampu berfikir dan bertindak sebagaimana yang diharapkan organisasi. Organisasi yang maju tentu dihasilkan oleh karyawan/pegawai yang dapat mengelola organisasi tersebut ke arah kemajuan yang diinginkan organisasi, sebaliknya tidak sedikit organisasi yang hancur dan gagal karena ketidakmampuannya dalam mengelola sumber daya manusia.

Agus (1994:3) dalam Gomes (2003:6) mengemukakan bahwa manajemen sumber daya manusia adalah perencanaan, pengorganisasian, pengarahan dan pengawasan atas pengadaan, pengembangan, pemberian kompensasi, pengintergrasian, pemeliharaan dan pemutusan hubungan tenga kerja dengan maksud untuk mencapai tujuan organisasi, individu, dan masyarakat. Sedangkan menurut Simamora (2004:4) manajemen sumber daya manusia adalah, "Pendayagunaan, pengembangan, penilaian, pemberian balas jasa, dan pengelolaan individu anggota organisasi atau kelompok karyawan, juga menyangkut desain dan implementasi sistem perencanaan, penyusunan karyawan, pengembangan karyawan, pengelolaan karir, evaluasi kinerja, kompensasi karyawan dan hubungan ketenagakerjaan yang baik.

\section{Kepuasan Kerja}

Kepuasan kerja (job satisfaction) adalah sebuah tanggapan efektif atau emosional terhadap berbagai segi pekerjaan seseorang. Definisi ini secara tidak langsung menyatakan bahwa kepuasan kerja bukanlah sebuah konsep kesatuan. Namun, seseorang bisa bisa merasa cukup puas dengan salah satu aspek pekerjaannya dan merasa kurang puas dengan satu atau beberapa aspek lainnya. (Robert dan Kinicki, 2014:169). Robbins and Timothy (2008:107) mengemukakan bahwa kepuasan kerja sebagai suatu perasaan positif tentang pekerjaan seseorang yang merupakan hasil dari sebuah evaluasi karakteristiknya.

Dari beberapa pengertian mengenai kepuasan kerja tersebut, dapat disimpulkan secara sederhana bahwa kepuasan kerja adalah perasaan seseorang 
terhadap pekerjaannya. Ini berarti bahwa konsepsi kepuasan kerja melihatnya sebagai hasil interaksi manusia terhadap lingkungan kerjanya.

\section{Motivasi}

Robbins and Timothy (2008:222) mengemukakan bahwa motivasi adalah proses yang menjelaskan intesitas, arah, dan ketekunan usaha untuk mencapai suatu tujuan. Menurut Ardana,dkk (2012:193) motivasi adalah "kekuatan yang mendorong seseorang untuk melakukan suatu tindakan atau tidak pada hakekatnya ada secara internal dan eksternal yang dapat positif atau negatif untuk mengarahkannya sangat bergantung kepada ketangguhan sang manajer".

Gomes (2003:180) menyatakan bahwa faktor - faktor yang mempengaruhi motivasi melibatkan faktor - faktor individual dan faktor - faktor organisasional. Yang tergolong pada faktor - faktor yang sifatnya individual adalah kebutuhan kebutuhan (needs), tujuan - tujuan (goals), sikap (attitudes), dan kemampuan kemampuan (abilities). Sedangkan yang tergolong pada faktor - faktor yang berasal dari organisasi meliputi pembayaran atau gaji (pay), keamanan pekerjaan (job security), sesama pekerjaan (co - workers), pengawasan (supervision), pujian (praise), dan pekerjaan itu sendiri (job it self).

\section{Kompensasi}

Pada dasarnya manusia bekerja dengan tujuan hidupnya. Seorang karyawan akan bekerja dan menunjukkan loyalitas terhadap perusahaan, Karena itu pula perusahaan memberikan penghargaan terhadap prestasi kerja karyawan yaitu dengan memberikan kompensasi. Salah satu cara manajemen untuk meningkatkan prestasi kerja, memotivasi dan meningkatkan kepuasan kerja para karyawan adalah melalui kompensasi.

Menurut Mondy (2008:4) menyatakan bahwa kompensasi adalah total seluruh imbalan yang diterima para karyawan sebagai pengganti jasa yang telah mereka berikan. Menurut Ardana,dkk (2012:153) kompensasi adalah "segala sesuatu yang diterima oleh karyawan sebagai balas jasa atas kontribusinya kepada perusahaan atau organisasi ". 


\section{Lingkungan Kerja}

Nitisemito (2006: 56) menyatakan lingkungan kerja adalah segala sesuatu yang ada di sekitar para pekerja yang dapat mempengaruhi kepuasaan dirinya dalam menjalankan tugas-tugas yang diembankan. Menurut Sutrisno (2009: 118) lingkungan kerja fisik adalah keseluruhan sarana dan prasarana kerja yang ada di sekitar pegawai yang sedang melakukan pekerjaan yang dapat mempengaruhi pelaksanaan pekerjaan.

Berdasarkan beberapa pendapat di atas, disimpulkan bahwa lingkungan kerja merupakan segala sesuatu yang ada di sekitar karyawan pada saat bekerja, baik yang berbentuk fisik ataupun non fisik, langsung atau tidak langsung, yang dapat mempengaruhi dirinya dan pekerjaanya saat bekerja.

\section{Peneltian Terdahulu}

Penelitian terdahulu yang dilakukan oleh Ida ayu Brahmasari dan Agus Suprayetno (2008) dapat ditarik kesimpulan bahwa motivasi kerja berpengaruh positif dan signifikan terhadap kepuasan kerja karyawan, artinya bahwa motivasi kerja memang sangat diperlukan oleh seseorang karyawan untuk dapat mencapai suatu kepuasan kerja yang tinggi meskipun menurut sifatnya kepuasan kerja itu sendiri besarnya sangat relatif atau berbeda antara satu orang dengan orang lainnya.

Berdasarkan penelitian yang dilakukan Fauzan Muttaqien (2014) variabel kompensasi mempunyai pengaruh yang dominan terhadap Kepuasan kerja Pegawai outsourcing PT. BRI (Persero), tbk. Cabang Lumajang. Dan penelitian yang dilakukan Intan Kusumaningtyas dan Alwi Suddin (2012) kompensasi financial dan kompensasi non financial memiliki pengaruh yang signifikan terhadap kepuasan kerja karyawan Bank Mega Cluster Surakarta.

Penelitian yang dilakukan Anak Agung Ngurah Bagus Dharmawan, I Gede Adayana Sudibya, dan I Wayan Mudhiarta Utama (2012) menyimpulkan bahwa lingkungan kerja dan kompensasi berpengaruh signifikan terhadap kepuasan kerja dan kinerja karyawan. Dan penelitian yang dilakukan I Dewa Gede Kresna 
Wirawan dan I Nyoman Sudharma menyimpulkan bahwa lingkungan kerja fisik berpengaruh positif signifikan terhadap kepuasan kerja pegawai pada Sekretariat Daerah Kota Denpasar.

\section{KERANGKA PEMIKIRAN}

Banyak faktor yang mempengaruhi kepuasan kerja. Faktor - faktor yang dapat mempengaruhi kepuasan kerja adalah motivasi, kompensasi, dan lingkungan kerja. Berdasarkan uraian diatas, maka dapat digunakan kerangka pemikiran sebagai berikut:

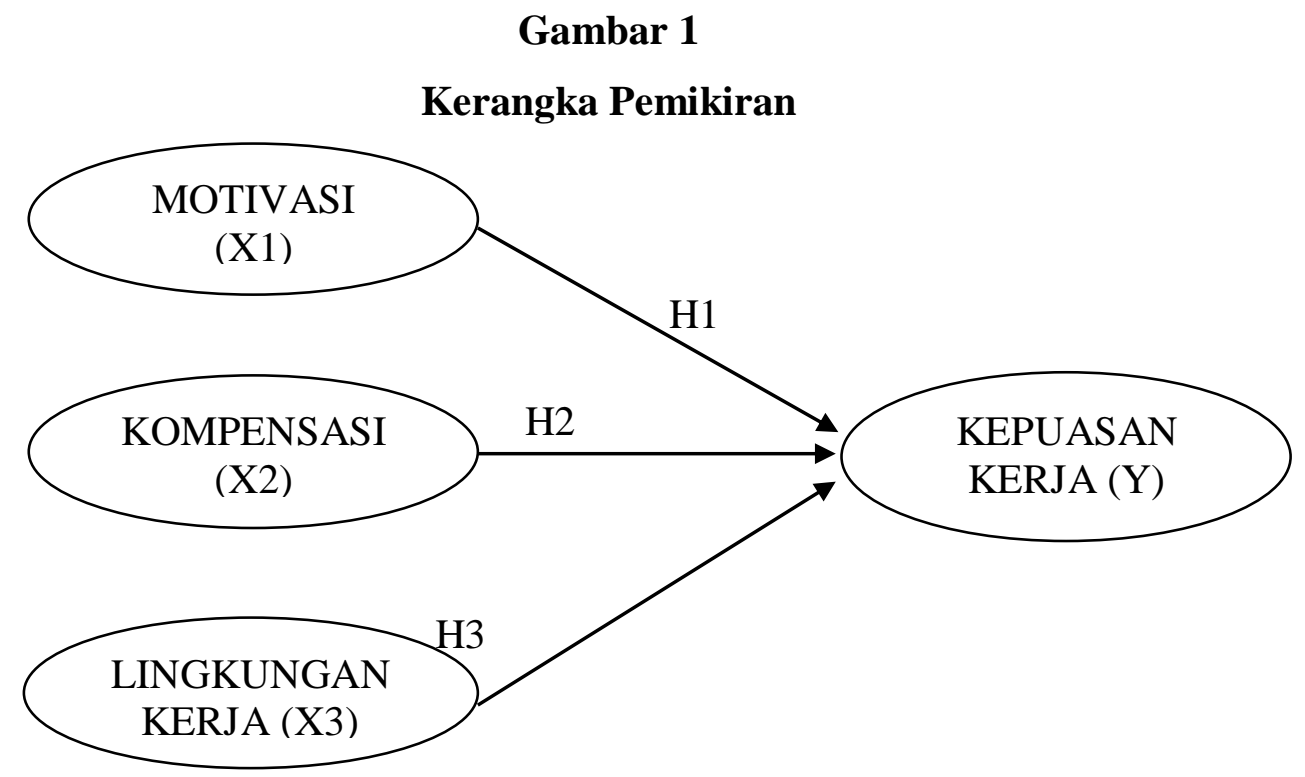

\section{HIPOTESIS}

H1: Motivasi berpengaruh positif terhadap kepuasan kerja

H2: Kompensasi berpengaruh positif terhadap kepuasan kerja

H3: Lingkungan kerja berpengaruh positif terhadap kepuasan kerja

\section{METODOLOGI PENELITIAN}

\section{Populasi dan Penentuan Sampel}


Populasi dalam penelitian ini adalah karyawan CV ENGGAL JAYA SEMARANG yang berjumlah 60 karyawan. Tekhnik yang digunakan dalam pengambilan sampel dalam penelitian ini adalah dengan menggunakan tekhnik sampling jenuh atau sensus, yaitu penentuan sampel bila semua anggota populasi digunakan sampel. Sampel dalam penelitian ini adalah seluruh populasi, yaitu seluruh karyawan CV ENGGAL JAYA SEMARANG yang berjumlah 60 karyawan.

\section{Jenis dan Sumber Data}

Adapun jenis data pada penelitian jika dilihat dari sumbernya adalah data primer yaitu data mengenai tanggapan karyawan CV ENGGAL JAYA SEMARANG mengenai motivasi, kompensasi, lingkungan kerja dan kepuasan kerja. Tanggapan karyawan tersebut diperoleh lewat kuesioner terhadap karyawan yang menjadi responden dalam penelitian ini.

\section{Metode Pengumpulan Data}

Metode pengumpulan data dalam penelitian ini menggunakan cara kuesioner. Jenis kuesioner yang digunakan dalam penelitian ini adalah kuesioner langsung tertutup yang berbentuk skala bertingkat, sehingga responden tinggal memilih pada kolom jawab yang telah disediakan mengenai pengaruh Motivasi, Kompensasi, dan Lingkungan Kerja terhadap Kepuasan Kerja Karyawan.

\section{Metode Analisis}

\section{Regresi Linear Berganda}


Metode analisis yang digunakan adalah regresi linear berganda. Pada penelitian ini menggunakan analisis regresi dengan persamaan atau model sebagai berikut:

$$
\begin{aligned}
& \mathrm{Y}=\mathrm{a}+\mathrm{b}_{1} \mathrm{X}_{1}+\mathrm{b}_{2} \mathrm{X}_{2}+\mathrm{b}_{3} \mathrm{X}_{3}+\mathrm{e} \\
& \text { Keterangan }: \\
& \mathrm{Y} \quad: \text { Kepuasan Kerja } \\
& \mathrm{a} \quad \text { : Konstanta } \\
& \mathrm{X}_{1} \quad \text { : Motivasi } \\
& \mathrm{X}_{2} \quad \text { : Kompensasi } \\
& \mathrm{X}_{3} \quad \text { : Lingkungan Kerja } \\
& \mathrm{b}_{1} \ldots \mathrm{b}_{3} \quad \text { : Koefisien } \mathrm{X}_{1} \ldots . \mathrm{X}_{3} \\
& \mathrm{e} \quad: \text { Error }
\end{aligned}
$$

\section{Uji Koefisien Determinasi atau Uji Adjusted $\mathbf{R}^{2}$}

Pengujian untuk Koefisien Determinasi atau Uji Adjusted $\mathrm{R}^{2}$ dilakukan untuk mengetahui kemampuan menjelaskan variabel $\mathrm{X}$ terhadap variabel $\mathrm{Y}$. Jadi semakin besar nilainya berarti pengaruhnya semakin besar dan sebaliknya.

\section{Uji Hipotesis (Uji t)}

Uji t digunakan untuk mengetahui seberapa jauh satu variabel bebas $\mathrm{X}$ secara individu dalam menerangkan variabel terikat Y.

Daerah kritis:

- Jumlah responden (n), jumlah variabel (k)

- Taraf signifikansi $\alpha=5 \%$

- $\quad$ Degree of Fredom $(\mathrm{df})=\mathrm{n}-\mathrm{k}-1$

- Uji satu sisi (ditunjukan pada hipotesis pengaruh yang positif)

Hipotesis: 
1) Apabila angka probabilitas signifikansi $>\alpha=0,05$ dan $\mathrm{t}$ hitung $<\mathrm{t}$ tabel, maka Ho diterima dan Ha ditolak.

Artinya tidak ada pengaruh positif dan signifikan antara motivasi (X1), kompensasi (X2), dan lingkungan kerja (X3) terhadap kepuasan kerja (Y).

2) Apabila angka probabilitas signifikansi $<\alpha=0,05$ dan thitung $>\mathrm{t}$ tabel, maka Ho ditolak dan Ha diterima.

Artinya ada pengaruh positif dan signifikan antara motivasi (X1), kompensasi (X2), dan lingkungan kerja (X3) terhadap kepuasan kerja (Y).

\section{HASIL DAN PEMBAHASAN}

Pada penelitian ini dilakukan pengujian hipotesis dengan menggunakan analisis regresi linear berganda dengan menggunakan bantuan program SPSS. Berikut ini adalah hasilnya:

\section{Tabel 1. Analisis Regresi (Uji t)}

\section{Coefficients $^{\mathrm{a}}$}

\begin{tabular}{|cl|l|l|l|l|l|}
\hline Model & & \multicolumn{2}{|l|}{$\begin{array}{l}\text { Unstandardized } \\
\text { Coefficients }\end{array}$} & $\begin{array}{l}\text { Standardized } \\
\text { Coefficients }\end{array}$ & $\mathrm{t}$ & Sig. \\
\cline { 3 - 6 } & & $\mathrm{B}$ & Std. Error & Beta & & \\
\hline & (Constant) &, 808 & 1,567 & &, 516 &, 608 \\
& MOTIVASI &, 185 &, 073 &, 208 & 2,537 &, 014 \\
& KOMPENSAS &, 582 &, 096 &, 605 & 6,063 &, 000 \\
& I & & & & 2,170 &, 034 \\
& LINGKUNGA &, 191 &, 088 &, 212 & & \\
\hline
\end{tabular}

a. Dependent Variable: KEPUASAN KERJA

Sumber : Data Primer yang diolah, 2016

Persamaan Regresi:

$Y=0,208 X_{1}+0,605 X_{2}+0,212 X_{3}$

Dimana:

$$
\begin{aligned}
Y & =\text { Kepuasan Kerja } \\
X 1 & =\text { Motivasi } \\
X & =\text { Kompensasi } \\
X & =\text { Lingkungan Kerja }
\end{aligned}
$$

Berdasarkan dari hasil uji t, maka dapat dilakukan pembuktian hipotesis sebagai berikut: 
1) Pengaruh motivasi terhadap kepuasan kerja

Diketahui signifikansi $\alpha=0,014<\alpha=0,05$ sehingga Ho ditolak atau Ha diterima. Artinya ada pengaruh positif dan signifikan antara motivasi terhadap kepuasan kerja.

2) Pengaruh kompensasi terhadap kepuasan kerja

Diketahui signifikansi $\alpha=0,00<\alpha=0,05$ sehingga Ho ditolak atau Ha diterima. Artinya ada pengaruh positif dan signifikan antara kompensasi terhadap kepuasan kerja.

3) Pengaruh lingkungan kerja terhadap kepuasan kerja

Diketahui signifikansi $\alpha=0,034<\alpha=0,05$ sehingga Ho ditolak atau Ha diterima. Artinya ada pengaruh positif dan signifikan antara lingkungan kerja terhadap kepuasan kerja.

Tabel 2. Perbandingan $t$ tabel dengan $t$ hitung

\begin{tabular}{|l|c|c|c|}
\hline \multicolumn{1}{|c|}{ Variabel } & t hitung & t tabel & Keterangan \\
\hline MOTIVASI (X1) & 2,537 & 2,002 & signifikan \\
\hline KOMPENSASI (X2) & 6,063 & 2,002 & signifikan \\
\hline $\begin{array}{l}\text { LINGKUNGAN KERJA } \\
\text { (X3) }\end{array}$ & 2,170 & 2,002 & signifikan \\
\hline
\end{tabular}

Sumber: Data Primer yang diolah, 2016

Dasar pengambilan keputusan:

Dari perbandingan tabel diatas, terlihat bahwa $t$ hitung $>\mathrm{t}$ tabel. Yang berarti ada pengaruh yang positif antara $X$ (Independen) berpengaruh secara signifikan dan positif terhadap variabel Y(Dependen).

\section{Hasil Pengujian Koefisien Determinasi}

Untuk mengetahui seberapa besar pengaruh variabel independen terhadap dependen dilakukan dengan uji koefisien determinasi dengan melihat pada nilai Adjusted R Square yaitu:

Tabel 3. Koefisien Determinasi Berganda $\left(\mathbf{R}^{2}\right)$ 


\begin{tabular}{|l|r|r|r|r|}
\hline Model & \multicolumn{1}{|c|}{$\mathrm{R}$} & R Square & \multicolumn{1}{|c|}{$\begin{array}{c}\text { Adjusted R } \\
\text { Square }\end{array}$} & $\begin{array}{c}\text { Std. Error of the } \\
\text { Estimate }\end{array}$ \\
\hline 1 &, $805^{\mathrm{a}}$ &, 648 &, 629 & 1,194 \\
\hline
\end{tabular}

A. Predictors: (Constant), LINGKUNGAN KERJA, MOTIVASI, KOMPENSASI

B. Dependent Variable: KEPUASAN KERJA

Sumber: Data Primer yang diolah, 2016

Besarnya koefisien determinasi dapat dilihat nilai Adjusted $R$ square yang menunjukan angka sebesar 0,629. Hasil ini menunjukan bahwa motivasi, kompensasi dan lingkungan kerja mampu mempengaruhi kepuasan kerja sebesar 62,9\%, sementara untuk 37,1\% kepuasan kerja dipengaruhi oleh variabel diluar motivasi, kompensasi, dan lingkungan kerja.

\section{Pembahasan}

\section{Pengaruh Motivasi Terhadap Kepuasan Kerja}

Hasil pengujian hipotesis $\left(\mathrm{H}_{1}\right)$ telah membuktikan terdapat pengaruh antara motivasi terhadap kepuasan kerja. Melalui hasil perhitungan yang telah dilakukan diperoleh nilai t hitung sebesar 2,537 dengan taraf signifikansi hasil sebesar 0,014 tersebut lebih kecil dari 0,05, yang berarti bahwa hipotesis dalam penelitian ini menerima Ha dan menolak Ho. Pengujian ini secara statistik membuktikan bahwa motivasi berpengaruh positif dan signifikan terhadap kepuasan kerja. Artinya bahwa ada pengaruh antara variabel motivasi terhadap kepuasan kerja karyawan CV Enggal Jaya Semarang.

\section{Pengaruh Kompensasi Terhadap Kepuasan Kerja}

Hasil pengujian hipotesis $\left(\mathrm{H}_{2}\right)$ telah membuktikan terdapat pengaruh antara kompensasi terhadap kepuasan kerja. Melalui hasil perhitungan yang telah dilakukan diperoleh nilai t hitung sebesar 6,063 dengan taraf signifikansi hasil sebesar 0,000 tersebut lebih kecil dari 0,05, yang berarti bahwa hipotesis dalam penelitian ini menerima Ha dan menolak Ho. Pengujian ini secara statistik membuktikan bahwa kompensasi berpengaruh positif dan signifikan terhadap 
kepuasan kerja. Artinya bahwa ada pengaruh antara variabel kompensasi terhadap kepuasan kerja karyawan CV Enggal Jaya Semarang.

\section{Pengaruh Lingkungan Kerja Terhadap Kepuasan Kerja}

Hasil pengujian hipotesis $\left(\mathrm{H}_{3}\right)$ telah membuktikan terdapat pengaruh antara lingkungan kerja terhadap kepuasan kerja. Melalui hasil perhitungan yang telah dilakukan diperoleh nilai t hitung sebesar 2,170 dengan taraf signifikansi hasil sebesar 0,034 tersebut lebih kecil dari 0,05, yang berarti bahwa hipotesis dalam penelitian ini menerima $\mathrm{Ha}$ dan menolak Ho. Pengujian ini secara statistik membuktikan bahwa lingkungan kerja berpengaruh positif dan signifikan terhadap kepuasan kerja. Artinya bahwa ada pengaruh antara variabel lingkungan kerja terhadap kepuasan kerja karyawan CV Enggal Jaya Semarang.

\section{PENUTUP}

\section{Kesimpulan}

Berdasarkan pada hasil analisis dan pembahasan, maka dapat ditarik kesimpulan sebagai berikut:

1. Ada pengaruh positif dan signifikan antara motivasi terhadap kepuasan kerja. Hal ini berarti apabila semakin tinggi motivasi untuk karyawan maka kepuasan kerja karyawan akan meningkat.

2. Ada pengaruh positif dan signifikan antara kompensasi terhadap kepuasan kerja. Hal ini berarti apabila kompensasi ditingkatkan maka kepuasan kerja karyawan akan meningkat.

3. Ada pengaruh positif dan signifikan antara lingkungan kerja terhadap kepuasan kerja. Hal ini berarti apabila kualitas lingkungan kerja semakin baik maka kepuasan kerja karyawan akan meningkat.

\section{Saran}

Saran yang bisa disampaikan berdasarkan dari hasil penelitian yang didapat untuk perusahaan adalah sebagai berikut : 
1. Sebaiknya pihak manajemen CV Enggal Jaya Semarang memberikan pekerjaan yang sesuai dengan keahlian yang dimiliki oleh karyawannya, sehingga apa yang dikerjakan oleh karyawan tersebut dapat dikuasai dan dipertanggung jawabkan atas kinerjanya.

2. Dalam upaya meningkatkan kompensasi, pihak manajemen CV Enggal Jaya Semarang sebaiknya memperhatikan kelayakan gaji dan menyesuaikannya dengan kemampuan karyawan saat ini,

3. Dalam hal lingkungan kerja, pihak manajemen CV Enggal Jaya Semarang sebaiknya memperhatikan keamanan lingkungan, lingkungan yang aman membuat karyawan yang bekerja merasa nyaman dan lebih fokus pada pekerjaanya .

\section{DAFTAR PUSTAKA}

Ardana, Komang, Ni Wayan Mujiati, dan I Wayan Mudiartha Utama. 2012. Manajemen Sumber Daya Manusia. Yogyakarta: Graha Ilmu.

Brahmasari, Ida dan Suprayetno, Agus. 2008. Pengaruh Motivasi Kerja, Kepemimpinan dan Budaya Organisasi Terhadap Kepuasan Kerja Karyawan serta Dampaknya pada Kinerja Perusahaan (Studi Kasus pada PT. Pei Hai International Wiratama Indonesia). Jurnal Manajemen dan Kewirausahaan, 10(2), h:124-135.

Dhermawan, Sudibya dan I Wayan Mudiartha Utama. 2012. Pengaruh Motivasi, Lingkungan Kerja, Kompetensi, dan Kompensasi Terhadap Kepuasan Kerja dan Kinerja Pegawai di Lingkungan Kantor Dinas Pekerjaan Umum Provinsi Bali, Jurnal Manajemen, Strategi Bisnis, dan Kewirausahaan, 6(2), h:173-184.

Ghozali, Imam, 2009. Aplikasi Analisis Multivariate Dengan Program SPSS. Edisi Keempat. Semarang: Badan Penerbit Universitas Diponegoro.

Ghozali, Imam. 2011. Aplikasi Analisis Multivariate dengan Program IBM SPSS 19. Semarang: Badan Penerbit Universitas Diponegoro. 
Ghozali, Imam. 2012. Aplikasi Analisis Multivariate dengan Program IBM SPSS 20. Semarang: Badan Penerbit Universitas Diponegoro.

Gomes, Faustino Cardoso. 2009. Manajemen Sumber Daya Manusia, edisi kedua. Yogyakarta: Andi.

Handoko, T. Hani. 2001. Manajemen Personalia dan Sumber Daya Manusia. Edisi Kedua. Yogyakarta: BPFE UGM

Kreitner, Robert dan Angelo Kinicki. 2014. Organizational behavioral-Ed. 5. Boston: McGraw-Hill.

Kusumaningtyas, Intan dan Suddin, Alwi. 2012. Pengaruh Kompensasi Terhadap Kepuasan Kerja Karyawan Bank Mega dengan Motivasi Kerja Sebagai Variabel Moderasi. Jurnal Manajemen Sumberdaya Manusia, 6(2), h:95-105.

Marzuki. 2003. Metodologi Riset. Yogyakarta: BPFE-UII.

Mathis, Robert L. Dan Jackson, John H. 2006. Manajemen Sumber Daya Manusia. Jakarta: Salemba Empat

Maznah, J. J. Ma'ruf, Sofyan Idris, (2012). Pengaruh Lingkungan Organisasi, Kepuasan Kerja terhadap Motivasi Kerja serta Implikasinya pada Kinerja Pegawai Politeknik Negeri Lhosumawe. Jurnal Ilmu Manajemen Pascasarjana Universitas Syiah Kuala.

Mondy, R. Wayne. 2008. Manajemen Sumber Daya Manusia. Jakarta: Erlangga

Murti, Harry dan Srimulyani, Veronika. 2013. Pengaruh Motivasi Terhadap Kinerja Pegawai dengan Variabel Pemediasi Kepuasan Kerja Pada PDAM Kota Madiun. Jurnal Riset Manajemen dan Akuntansi, 1(1), h:10-17.

Muttaqien, Fauzan. 2014. Pengaruh Kepemimpinan dan Kompensasi Terhadap Kepuasan Kerja Karyawan Outsourcing Pada PT. BRI (Persero), tbk. Cabang Lumajang. Jurnal WIGA, 4(1), h:19-33.

Alek S. Nitisemito, 2006, Manajemen Personalia Edisi Kedua, Ghalia Indonesia. Husaini Usman dan R. Purnomo Setiady Akbar. 2006. Pengantar Statistika. Jakarta: Bumi Aksara. 
Rahmawati, Swasto dan Arik Prasetya. 2014. Pengaruh Lingkungan Kerja Terhadap kinerja karyawan (Studi pada Karyawan Kantor Pelayanan Pajak Pratama Malang Utara). Jurnal Administrasi Bisnis, 8(2), h:1-9.

Robbins, Stephen P. dan Timothy A. Judge. 2008. Perilaku Organisasi Edisi ke-12, Jakarta: Salemba Empat.

Sarjono, H and Julianita, W. 2013. SPSS vs Lisrel; sebuah pengantar, aplikasi untuk riset. Jakarta: Salemba Empat.

Siagian, SP. 2000. Manajemen Sumber Daya Manusia. Jakarta: Bumi Aksara.

Simamora, H. 2004. Manajemen Sumberdaya Manusia Edisi III. Bagian Penerbit Sekolah Tinggi Ilmu Ekonomi YKPN, Yogyakarta.

Sugiyono. 2009. Metode Penelitian Bisnis (Pendekatan Kuantitatif, Kualitatif, dan $R \& D)$. Bandung: Alfabeta.

Sugiyono. 2010. Metode Penelitian Kuantitatif, Kualitatif, dan $R \& D)$. Bandung: Alfabeta.

Sugiyono. 2015. Metode Penelitian Pendidikan (Pendekatan Kuantitatif, Kualitataif, dan $R \& D)$. Bandung: Alfabeta.

Sutrisno, Edi. 2009. Manajemen Sumber Daya Manusia Edisi pertama. Jakarta: Kencana Prenada Media Group

Widyono, Didi dan Musafik, Naim. 2013. Pengaruh Kompensasi Terhadap Kepuasan Kerja Pegawai (Studi Kasus Pada Guru SD di Kecamatan Campurdarat Kabupaten Tulungagung). Jurnal OTONOMI, 13(3), h:1-13.

Wirawan, Kresna dan Nyoman, Sudharma. 2015. Pengaruh Komunikasi, Motivasi, dan Lingkungan Kerja Fisik Terhadap Kepuasan Kerja Pegawai Sekretariat Daerah Kota Denpasar. E-Jurnal Manajemen Unud, 4(10), h:3037-3036. 